\title{
Novas espécies e notas sobre Cerambycidae (Coleoptera) do Pará e do nordeste do Brasil
}

\author{
Maria Helena M. Galileo ${ }^{1,3}$ \& Ubirajara R. Martins ${ }^{2,3}$
}

\author{
${ }^{1}$ Museu de Ciências Naturais, Fundação Zoobotânica do Rio Grande do Sul, Caixa Postal 1188, 90001-970 Porto Alegre, \\ Rio Grande do Sul, Brasil. \\ ${ }^{2}$ Museu de Zoologia, Universidade de São Paulo. Caixa Postal 42594, 04299-970 São Paulo, São Paulo, Brasil. \\ ${ }^{3}$ Bolsista do CNPq.
}

\begin{abstract}
New species and notes on Cerambycidae (Coleoptera) from Pará and Brazilian norteastern. Based on material collected by P. Jauffert in Pará and by L. lanuzzi in Alagoas and Sergipe, four new species are described: Temnopis fasciata sp. nov. (Oemini) and Dihammaphoroides jaufferti sp. nov. (Cleomenini) from Pará. This species breads in branches of Pseudopiptadenia suaveolens (Miq.) J. W. Grimes, Fabaceae. Adetus tuberosus sp. nov. (Apomecynini) and Mimasyngenes lucianae sp. nov. (Desmiphorini) from Alagoas. New records and notes are provided for Neocompsa serrana (Martins, 1962) and Rhopalophora occipitalis Chevrolat, 1859.
\end{abstract}

KEY WORDS. Cerambycinae, Lamiinae, Pseudopiptadenia.

Reuniu-se nesta contribuição material originário de duas fontes: (1) procedente de Alagoas e Sergipe colecionado pela Profa Luciana Iannuzzi na região da Represa de Xingó (Projeto Xingó de Biodiversidade, Universidade Federal de Pernambuco); (2) procedente do Pará, Santo Antônio do Tauá, coligido pelo Sr. Pierre Jauffert.

Esse material permitiu a descrição de duas espécies novas do Pará, Temnopis fasciata e Dihammaphoroides jaufferti cuja planta-hospedeira é Piptadenia suaveolens (Miq.) J.W. Grimes, Fabaceae. Descreve-se duas espécies inéditas da região da Represa de Xingó, no rio São Francisco, e dos estados de Alagoas e Sergipe: Adetus tuberosus e Mimasyngenes lucianae; inclui-se ainda, notas e novos registros para Neocompsa serrana (Martins, 1962) e Rhopalophora occipitalis Chevrolat, 1859.

As referências bibliográficas sob cada táxon restringemse à descrição original e ao catálogo de MonNé (1993, 1994).

O material foi depositado nas seguintes instituições: Coleção P. Jauffert, Santo Antônio do Tauá, Pará (CPJP); Museu de Ciências Naturais, Fundação Zoobotânica do Rio Grande do Sul, Porto Alegre (MCNZ); Museu Paraense Emílio Goeldi, Belém (MPEG); Museu de Zoologia, Universidade de São Paulo (MZSP).

Todas as medidas são fornecidas em milímetros.

\section{Cerambycinae Oemini Temnopis fasciata sp. nov. Fig. 1}

Fêmea. Tegumento corporal avermelhado-escuro; élitros (Fig. 1) vermelho-alaranjados, cada um com duas faixas longi- tudinais pretas: uma sutural e outra iniciada no úmero, percorre pequena extensão no dorso (até cerca do sétimo basal do élitro) e depois funde-se com a margem até o ápice. Espículo dos lados do protórax curto e menos aguçado do que nas fêmeas de T. megacephala. Processo prosternal inicia-se abaixo da superfície prosternal (MARTINs 1997: 80, fig. 80). Antenômeros IX-XI, perna anterior esquerda, perna intermediária esquerda e pernas posteriores estão quebradas no holótipo

Dimensões, fêmea. Comprimento total, 13,8; comprimento do protórax, 1,9; maior largura do protórax, 2,5; comprimento do élitro, 10,6; largura umeral, 3,0

Material-tipo. Holótipo fêmea procedente do Brasil, Pará: Santo Antônio de Tauá (Reserva Sonho Azul), 15.XII.1992, P. Jauffert leg., armadilha luminosa (MZSP).

Discussão. Temnopis fasciata sp. nov. assemelha-se a $T$. megacephala (Germar, 1824) e T. latifascia Martins \& Monné, 1975 pelo padrão de colorido elitral. Em ambas as espécies, os élitros são amarelados e, cada um, apresenta duas faixas longitudinais escuras, uma sutural outra paralela e próxima à margem, mas não contígua (isto é, não envolve o friso marginal). Em T. fasciata a faixa escura lateral inicia-se no úmero, percorre até o sétimo basal separada da margem e depois junta-se com a margem até o ápice, inclusive sobre o friso marginal. Por outro lado, tanto T. megacephala quanto T. latifascia vivem na Mata Atlântica desde o Rio Grande do Norte até a Argentina (Misiones) e T. fasciatus habita a Amazônia oriental. Além disso, difere de T. megacephala pelo colorido mais escuro do corpo e dos apêndices e distingue-se de T. latifascia pelo colorido mais claro. O conhecimento das antenas dos machos, eventualmente, fornecerá outros caracteres diferenciais.

Revista Brasileira de Zoologia 20 (3): 475-478, setembro 2003 


\section{Ibidionini \\ Neocompsa serrana Martins, 1962}

Compsa serrana Martins, 1962: 140, fig. 3.

Neocompsa serrana; Martins, 1965: 100; Monné, 1993: 66 (cat.).

Neocompsa serrana foi originalmente descrita da Serra do Urucum, Corumbá, Mato Grosso do Sul. Posteriormente, MARTINS (1970: 1125) mencionou exemplares procedentes da localidade-tipo coligidos durante a Expedição da Universidade de Cornell, USA, em 1919, e exemplares de Mato Grosso (do Sul?), coletados em 1886 por P. Germain.

O espécime agora examinado é procedente de Sergipe, área distante daquelas das ocorrências do material até então conhecido.

Material examinado. BrasiL, Alagoas: Olho d'Água do Casado (Fazenda Capelinha), macho, 18.V.2000, L. Ianuzzi leg., em armadilha de Malaise (MZSP).

\section{Rhopalophorini Rhopalophora occipitalis Chevrolat, 1859}

Rhopalophora occipitalis Chevrolat, 1859: 59; Monné, 1994: 5 (cat.).

Segundo Chevrolat (1859), esta espécie assemelha-se "assez notablement" a $R$. collaris (Germar, 1824), mas difere pelo occipício avermelhado e pelas dimensões menores. $\mathrm{Na}$ realidade, $R$. occipitalis assemelha-se mais a $R$. paraensis Martins \& Napp, 1989, originalmente descrita do Pará (Serra Norte), que não apresenta occipício avermelhado e tem a pubescência elitral mais adensada.

Material examinado. BRASIL, Sergipe: Canindé do São Francisco (Fazenda Bom Jardim), fêmea, 7.IX.2000, L. Iannuzzi leg., em armadilha de Malaise (MZSP); (Fazenda Esplanada), fêmea, 17.VIII.2000, L. Iannuzzi leg., em armadilha de Malaise (MZSP).

\section{Cleomenini Dihammaphoroides jaufferti sp. nov. Figs 2,3}

Etimologia. O nome específico é uma homenagem a Pierre Jauffert a quem devemos inúmeros favores e coletor da espécie.

Cabeça preta, glabra e densamente pontuada; os pontos microesculturados. Lobos oculares superiores tão distantes entre si quanto o quíntuplo da largura de um lobo. Lobos oculares inferiores com 2,5 vezes o comprimento das genas. Antenas pretas, nos machos atingem a ponta dos élitros; nas fêmeas, alcançam o quarto apical. Escapo subcilíndrico, curto, densamente pontuado; comprimento igual à metade do antenômero III. Antenômero III sulcado e carenado, com quase o dobro do comprimento do IV; este $1 / 3$ mais curto do que o V. Antenômeros V-VI sublineares; VIII-X curtos, sem sulco e angulosos no ângulo externo. Protórax vermelho. Pronoto com pontuação alveolada; o interior dos pontos microesculturado. Prosterno pontuado na metade posterior. Centro do processo prosternal com 1/4 do diâmetro de uma procoxa. Élitros pretos (vide variabilidade, figuras 2,3 ), com leve reflexo azulado metálico; pontuação muito fina e muito densa em toda a superfície; presença de carena longitudinal, dorsal, muito pouco elevada. Declividade lateral dos élitros vertical no lado da margem. Extremidades elitrais obliquamente truncadas com espinho curto no ângulo sutural. Pernas pretas. Metatíbias sulcadas no lado externo. Metatarsômero I tão longo quanto II+III. Face ventral do corpo preta revestida por pubescência esbranquiçada. Metepisternos pontuados.

Variabilidade. Duas fêmeas, que atribuímos á espécie, apresentam os élitros (Fig. 3) amarelados, enegrecidos apenas no quarto apical. Nas demais características coincidem com a forma típica.

Dimensões, respectivamente macho/fêmea. Comprimento total, 5,6/6,0-7,1; comprimento do protórax, 1,1/1,2-1,5; maior largura do protórax, 1,0/1,0-1,3; comprimento do élitro, 4,1/4,3-5,2; largura umeral, 1,1/1,1-1,4.

Material-tipo. Holótipo macho procedente do BrasiL, Pará: Santo Antônio do Tauá (Reserva Sonho Azul), 13.VII.2001, Pierre Jauffert leg. (MZSP). Parátipos: mesma procedência e coletor do holótipo, macho, 17,VI.2001 (MCNZ); macho, fêmea, 20.VI.2001 (MPEG); fêmea, 20.VI.2001 (CPJP); fêmea, 22.VI.2002, "ex larva Pseudopiptadenia suaveolens" (MCNZ); macho, 25.VI.2001 (CPJP); fêmea, 8.VII.2002, "ex larva Pseudopiptadenia suaveolens" (MZSP); fêmea, 16.VII.2001; macho, 26.VII.2001 (MZSP); fêmea, 23.VIII.2001 (MZSP). Ilha de Colares, macho, 30.VII.2002, P. Jauffert leg. (MZSP). Ulianópolis (Fazenda São Lucas), fêmea, 1.IV.2002, P. Jauffert leg., "de ramo cortado p/ Oncideres encontrado XII.01" (MZSP).

Discussão. O gênero Dihammaphoroides foi estabelecido por ZaJCIW (1967) para única espécie, D. sanguinicollis, descrita do Rio de Janeiro, Itatiaia. D. jaufferti difere de D. sanguinicollis por apresentar a relação de comprimento entre o protórax e dos élitros menor; em $D$. jaufferti a relação comprimento do élitro/comprimento do protórax é 3,6 e em $D$. sanguinicollis 3,8 ; em $D$. jaufferti o protórax é unicolor enquanto que em $D$. sanguinicollis apresenta mancha preta na base ou faixa preta central em toda extensão.

\section{Lamiinae Apomecynini Adetus tuberosus sp. nov. Fig. 4}

Cabeça, protórax e élitros com tegumento acastanhado recoberto por densa pubescência amarelada, entremeada por numerosas áreas, pequenas, de pubescência mais esparsa, conferindo aspecto de pequenas áreas escuras (Fig. 4); extremidades elitrais com mancha sutural, pequena, de pubescência castanho-escura; principalmente no terço apical, a pubescência amarelada é entremeada por pequenas manchas de pubescência branca mais alongada. Olhos divididos, lobos inferiores com menos de um terço do comprimento da gena. Antenas com tegumento avermelhado, coberto por pubescência amarelada, densa. Escapo e antenômero III com pubescência acastanhada no lado externo. Antenômeros VI-X amarelados com base castanha; XI acastanhado. Protórax apenas mais longo do que largo. Pontuação do pronoto não aparente, acobertada pela pubescência. Processo prosternal com tubérculo. Mesosterno arredondado na frente, não truncado. Metepisterno com tegumento preto. Pernas, médias e posteriores, predominantemente acastanhadas, variegadas de amarelado. Tíbias engrossadas. Lados dos dois primeiros urosternitos com manchas pretas. 

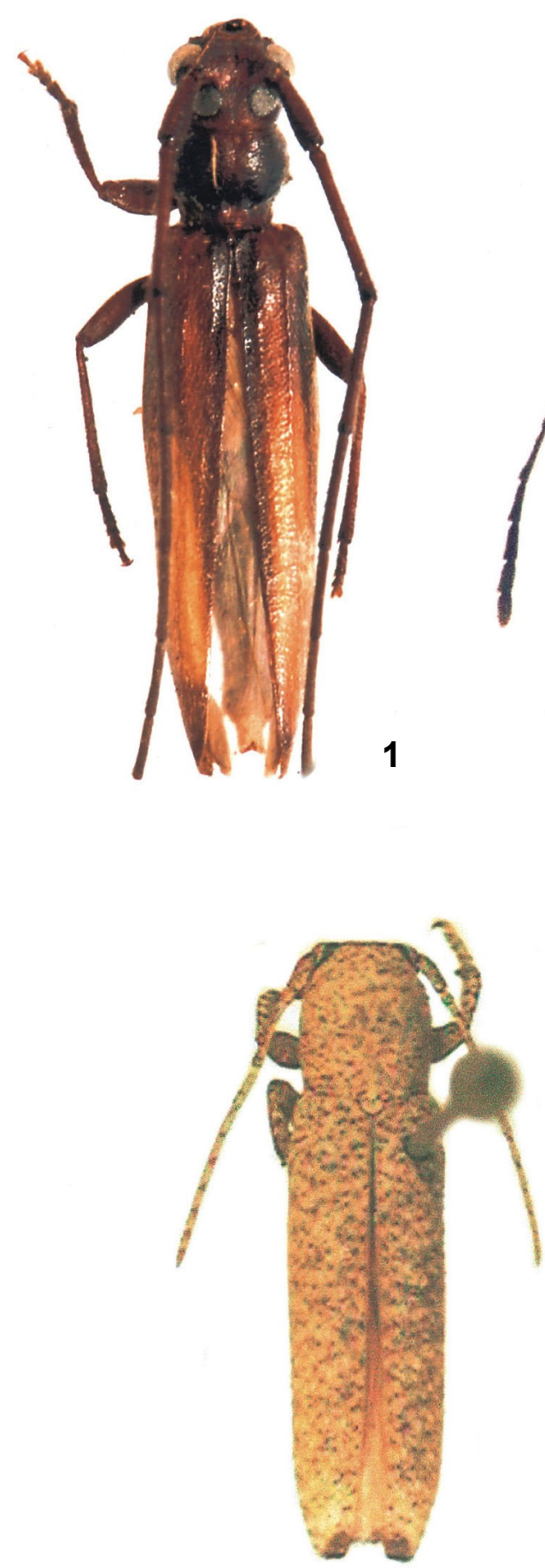

\section{4}

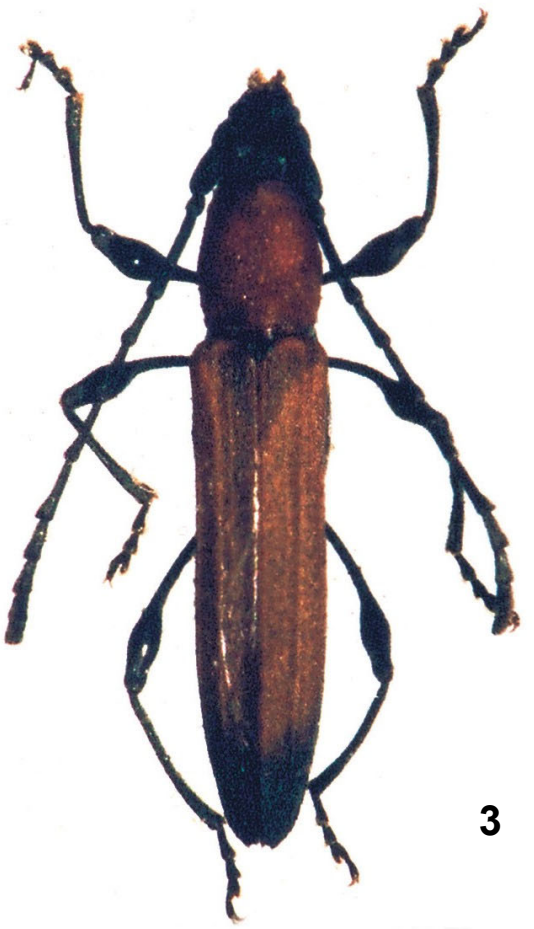

3

Figs 1-5. (1) Temnopis fasciata, holótipo fêmea, comprimento 13,8; (2-3) Dihammaphoroides jaufferti: (2) holótipo macho, comprimento 5,6; (3) parátipo fêmea, comprimento 6,7; (4) Adetus tuberosus, holótipo macho, comprimento10,9; (5) Mimasyngenes lucianae, holótipo fêmea, comprimento 4,4 . 
Dimensões. Comprimento total, 10,9; comprimento do protórax, 2,3; maior largura do protórax, 2,2; comprimento do élitro, 7,9; largura umeral, 2,6.

Material-tipo. Holótipo macho procedente do BrasIL, Alagoas: Olho d'Água do Casado (Fazenda Capelinha), 14.VII.2000, L. Iannuzzi leg., em armadilha de Malaise (MZSP).

Discussão. O aspecto do corpo lembra o de A. angustus Melzer, 1934 que também tem mancha escura pequena no ápice dos élitros. Entretanto, a espécie de Melzer não tem tubérculo no processo prosternal e a coloração geral é muito diferente.

\section{Desmiphorini Mimasyngenes lucianae sp. nov. Fig. 5}

Etimologia. O nome específico é uma homenagem a Luciana Iannuzzi coordenadora do projeto Xingó de Biodiversidade.

Tegumento vermelho-acastanhado. Face dorsal do corpo e apêndices com setas pretas e longas. Cabeça com pubescência relativamente longa, principalmente no vértice. Lobos oculares superiores mais afastados entre si do que a largura de um lobo. Flagelômeros castanhos com bases amareladas. Antenômero III pouco menor que o comprimento do escapo. Protórax castanho-avermelhado. Pronoto densamente pontuado, com pêlos dirigidos para os lados. Lados do protórax com espinho desenvolvido e dirigido para trás; sencilas implantadas em tubérculos, localizadas adiante e atrás do espinho. Cada élitro (Fig. 5) com pequena mancha de pubescência esbranquiçada e de contornos irregulares ao redor do escutelo; uma área de pubescência branca, também com bordas irregulares, na parte lateral do terço anterior, (semelhante a faixas longitudinais fundidas); uma área no terço apical que também assemelha-se à fusão de faixas longitudinais. Tíbias vermelho-amareladas com ápices escurecidos. Tarsos enegrecidos.

Dimensões, fêmea. Comprimento total, 4,6-4,4; comprimento do protórax, 0,9-0,8; maior largura do protórax, 1,41,3; comprimento do élitro, 3,4-3,1; largura umeral, 1,8-1,7.

Material-tipo. Holótipo fêmea procedente do BrasiL, Sergipe: Canindé do São Francisco (Fazenda Poço Verde), 8.IV. 2000, L. Iannuzzi leg., em armadilha Malaise (MZSP). Parátipo fêmea, com os mesmos dados do holótipo (MZSP).

Discussão. Galileo \& Martins (1996), ao revisarem o gênero Mimasyngenes, apresentaram chave para identificação das seis espécies que o constituíam. Essas espécies têm vasta distribuição (Colômbia até Argentina), mas somente M. lineatipennis ocorre no nordeste do Brasil (Pernambuco). M. lucianae, a sétima espécie do gênero, também ocorre no nordeste brasileiro (Sergipe) e separa-se de M. lineatipennis: pelo padrão do colorido dos élitros com uma mancha de pubescência branca, lateral, de contornos irregulares na metade anterior, uma faixa acastanhada, transversal, no meio dos élitros que não alcança a sutura e o terço apical com área branca de contornos bem irregulares; pela pubescência da cabeça e do protórax muito manifesta; pelos flagelômeros nitidamente anelados; pelo antenômero III apenas mais curto do que o escapo. Em $M$. lineatipennis, as faixas de pubescência branca dos élitros são mais ou menos contínuas da base ao ápice; pubescência da cabeça e do protórax quase inaparente; flagelômeros são unicolores, o antenômero III tem aproximadamente a metade do comprimento do escapo. Os mesmos caracteres, exceto o comprimento do antenômero III, diferenciam $M$. lucianae de $M$. quiuira.

\section{AGRADECIMENTOS}

À Profa Luciana Iannuzzi, Departamento de Zoologia, Centro de Ciências Biológicas, Universidade Federal de Pernambuco, Recife e ao Sr. Pierre Jauffert, Santo Antonio do Tauá, Pará, pelo empréstimo e doação do material. A Antonio Santos Silva (MZSP) e Rafael Santos de Araújo (MCNZ) pela execução das fotografias.

\section{REFERÊNCIAS BIBLIOGRÁFICAS}

Chevrolat, L.A.A. 1859. Essai monographique sur le genre Rhopalophora. Arcana Natura, Paris, 1: 57-64.

Galileo, M.H.M. \& U.R. Martins. 1996. Notas e descrições em Desmiphorini, com uma revisão do gênero Mimasyngenes Breuning. Revista Brasileira de Zoologia, Curitiba, 13 (4): 867-882.

Martins, U.R. 1962. Ibidionini (Coleoptera, Cerambycidae) XVIII. Um novo gênero e novas espécies. Papéis Avulsos do Departamento de Zoologia, São Paulo, 15 (13): 127162.

1965. Ibidionini (Coleoptera, Cerambycidae) XXIV. Divisão do gênero Compsa Perty, 1832. Papéis Avulsos do Departamento de Zoologia, São Paulo, 17 (9): 90-107.

. 1970. Monografia da tribo Ibidionini. Parte IV. Arquivos de Zoologia, São Paulo 16 (4): 879-1149.

. 1997. Cerambycidae Sul-Americanos. Taxonomia. Subfamília Cerambycinae: Oemini, Methiini, Dodecosini, Paraholopterini. São Paulo, Sociedade Brasileira de Entomologia, vol. 1, 217p.

Martins, U.R. \& D.S. NapP. 1989. Rhopalophorini: descrições, sinonímias e novas cobinações. Revista Brasileira de Entomologia, São Paulo, 33 (1): 57-65.

Monné, M.A. 1993. Catalogue of the Cerambycidae (Coleoptera) of the Western Hemisphere. Part V. São Paulo, Sociedade Brasileira de Entomologia, 100p.

. 1994. Catalogue of the Cerambycidae (Coleoptera) of the Western Hemisphere. Part X. São Paulo, Sociedade Brasileira de Entomologia, 81p.

ZAJcIw, D. 1967. Novos longicórneos neotrópicos. XIII. (Coleoptera, Cerambycidae, Cerambycinae). Memórias do Instituto Oswaldo Cruz, Rio de Janeiro, 65 (2): 197-204.

Recebido em 06.III.2003; aceito em 20.VIII.2003.

Revista Brasileira de Zoologia 20 (3): 475-478, setembro 2003 